\title{
RESEARCH IN INFLAMMATORY BOWEL DISEASES IN LATIN AMERICA: a challenge ahead
}

Kotze PG. Research in inflammatory bowel diseases in Latin America: a challenge ahead. Arq Gastroenterol. 2014,51(4):269-70. HEADINGS - Inflammatory bowel diseases. Crohn disease. Ulcerative colitis.

Inflammatory bowel diseases (IBD), namely ulcerative colitis (UC) and Crohn's disease (CD), are unspecified immunomediated clinical entities that remain a significant challenge for gastroenterologists even in the 21 st century ${ }^{(1,4)}$. Despite recent advances in the management strategies (treat-to-target, top-down, etc.) and new therapeutic options (such as new biological agents as vedolizumab and golimumab), there is still an important room for improvement in patient care $^{(5)}$. Most of the research in the IBD field focus not only in therapeutics but also in the ethiopatogenesis, as epidemiological data is well documented in several regions of the world.

However, research in the IBD field in Latin America still needs significant improvement. Few studies in the past 15 years contributed to the epidemiology of both CD and UC in this region of the world, and some observational retrospective case series and other cohort studies were also published among Latin American countries ${ }^{(2,8)}$. Several IBD Latin American centres contribute for international clinical trials, and developed deep expertise in the last years. The continent represents a significant part of the world, and the incidence of IBD is growing in this area. In the years to come, a larger number of patients will be in some form of treatment. The strategies for IBD management in Latin America is mostly based on guidelines from Europe and the United States, mostly due to the concentration of the publications in these countries.

In a simple search performed in international and
Latin American databases, such as Pubmed and Scielo, with the keywords [Crohn's disease], [Ulcerative colitis] and [Latin America], one can realize the small sample of studies in all IBD fields coming from referral centres that manage both $\mathrm{UC}$ and $\mathrm{CD}^{(6,7)}$. Mexico, Brazil and Argentina contributed scientifically with good information and take the lead in this continent, but there is still a huge space for improvement in the number and scientific level of the articles.

In this issue of Arquivos de Gastroenterologia, Farrukh and Mayberry described a simple review of the IBD data from Latin American countries ${ }^{(3)}$. The lack of studies cited in the paper is alarming, and improvement in the development of IBD research in this region of the world is a real need.

In this interesting review article, the authors also point out that the situation in central and South America is quite similar to what occurred in Portugal and Spain a couple of decades ago. They expect that the incidence of IBD in the new world can really increase in the years to come, and try to stimulate local physicians to focus in research in both $\mathrm{UC}$ and $\mathrm{CD}$, and correlate that even the ethiology of these entities can be clarified in areas where IBD research programmes are still embrionary ${ }^{(3)}$.

To date, the Brazilian study group of IBD (GEDIIB) is working in a project to build a national registry of patients, that can upgrade the level of local research in the field, and bring solid and trustable epidemiological data in such a heterogeneous country as Brazil. Moreover, in october 2014, the Panamerican Crohn's

Disclosure: Paulo Gustavo Kotze is a speaker and consultant for Abbvie, Janssen-Cilag, Ferring, Astrazeneca and Takeda. He is also consultant and did clinical research for Pfizer and received scientific support from Ethicon.

* Unidade de Cirurgia Colorretal, Hospital Universitário Cajuru - PUCPR, Curitiba, PR, Brasil. 
and Colitis Organisation (PANCCO) starts its activites, with the aim to unite efforts between Latin American countries, that can really start IBD research programmes which can outline the real situation of these inflammatory conditions in this region of the world.

In conclusion, the article from Farrukh and Mayberry, in addition to this editorial, represent a challenge to Latin American IBD experts. We need to improve the scientific level of IBD data in our countries, and we hope that an increase in the number of studies related to multiple aspects from CD and UC can be observed in a near future. Several factors can stimulate the development of IBD in central and South America, such as support from pharmaceutical companies and integration between European and North American experts with local Latin American researchers. It is definitely time to start.

Paulo Gustavo KOTZE*

Kotze PG. Pesquisa nas doenças inflamatórias intestinais na América Latina: um desafio à frente. Arq Gastroenterol. 2014,51(4):269-70.

DESCRITORES - Doenças inflamatórias intestinais. Doença de Crohn. Colite ulcerativa.

\section{REFERENCES}

1. Baumgart DC, Sandborn WJ. Crohn's Disease. Lancet. 2012;380:1590-605.

2. Bosques-Padilla FJ, Sandoval-García ER, Martínez-Vázquez MA, Garza-González E, Maldonado-Garza HJ. Epidemiology and clinical characteristics of ulcerative colitis in north-eastern Mexico. Rev Gastroenterol Mex. 2011;76:34-8.

3. Farrukh A, Mayberry JF. Inflammatory bowel disease in Hispanic communities: a concerted South American approach could identify the aetiology of Crohn's disease and ulcerative colitis. Arq Gastroenterol. 2014,51:(4)271-5.

4. Ordás I, Eckmann L, Talamini M, Baumgart DC, Sandborn WJ. Ulcerative Colitis. Lancet. 2012;380:1606-19.
5. Panaccione R, Hibi T, Peyrin-Biroulet L, Schreiber S. Implementing changes in clinical practice to improve the management of Crohn's disease. J Crohns Colitis. 2012;6(Suppl 2):S235-42.

6. PubMed. [Internet]. [accessed in 2014 August 21]. Available from: http://www. ncbi.nlm.nih.gov/pubmed/

7. Scientific Electronic Library Online. [Intenet]. [accessed in 2014 August 21]. Available from: http://www.scielo.br/

8. Victoria CR, Sassak LY, Nunes HR. Incidence and prevalence rates of inflammatory bowel diseases, in midwestern of São Paulo State, Brazil. Arq Gastroenterol. 2009;46:20-5. 